\title{
A Novel Ceruloplasmin Mutation Identified in a Chinese Patient and Clinical Spectrum of Aceruloplasminemia Patients
}

\author{
Wan-Qing Xu \\ Zhejiang University School of Medicine \\ Wang Ni \\ Zhejiang University School of Medicine \\ Rou-Min Wang \\ Zhejiang University School of Medicine \\ Yi Dong \\ Zhejiang University School of Medicine \\ Zhi-ying Wu ( $\nabla$ zhiyingwu@zju.edu.cn ) \\ Zhejiang University School of Medicine https://orcid.org/0000-0003-2106-572X
}

\section{Research Article}

Keywords: aceruloplasminemia, clinical spectrum, ceruloplasmin, novel variant, Chinese

Posted Date: April 20th, 2021

DOI: https://doi.org/10.21203/rs.3.rs-398274/v1

License: (c) (7) This work is licensed under a Creative Commons Attribution 4.0 International License. Read Full License

Version of Record: A version of this preprint was published at Metabolic Brain Disease on August 4th, 2021. See the published version at https://doi.org/10.1007/s11011-021-00799-0. 


\section{Abstract}

Background and Purpose: Aceruloplasminemia (ACP) is a rare disorder of iron overload resulting from ceruloplasmin (CP) variants. Because of its rarity and heterogeneity, the diagnosis of ACP is often missed or misdiagnosed. Here, we aim to present a clinical spectrum of ACP and raise more attention to the early diagnosis.

Methods: Whole exome sequencing (WES) was performed in a Chinese female patient suspected with ACP and her clinical data were collected in detail. The PubMed databases was searched for published ACP patients within the last decade, and we present a systematic review of their clinical features with data extracted from these researches.

Results: A novel pathogenic variant (c.2689delC) and a known pathogenic variant (c.606dupA) within ceruloplasmin gene were identified in our patient and confirmed the diagnosis of ACP. Then we reviewed 50 ACP patients including the case we reported here. A possible timeline of symptoms was discovered, anemia appears first (29.7 years old on average), followed by diabetes ( 37.3 years old) and finally neurological symptoms (52.2 years old). The delay in diagnosis was significantly shortened in patients without neurological symptoms. Biochemical triad including anemia, low to undetectable serum ceruloplasmin, low serum iron and/or hyperferritinemia, showed better sensitivity in diagnosis than clinical triad including diabetes, neurological symptoms and retinal degeneration.

Conclusions: Due to the variable symptom spectrum, patients with ACP often visit different departments, which can lead to misdiagnosis. Clinical attention needs to be paid to symptoms and tests that have a warning effect. Prompt diagnosis in the early stage of the disease can be beneficial.

\section{Introduction}

Aceruloplasminemia (ACP) is a rare (1:2,000,000 in Japan, unavailable in the rest of the world) autosomal recessive disorder of iron overload resulting from pathological variants within $C P$ gene that causes wide range of progressive clinical manifestations including anemia, diabetes mellitus, liver disease, retinal degeneration, and neurological symptoms.(Miyajima and Hosoi 1993) Ceruloplasmin (CP), the protein encoded by $C P$, is essential for regulating the homeostasis of copper and iron ions in human body. Lack of CP causes iron mediated oxidative damage and pathological cellular iron retention,(Wang and Wang 2019) and eventually leads to iron deposition in related organs and associated symptoms. To date, a total of 74 pathological variants within $C P$ were reported according to Human Gene Mutation Database Professional (https://portal.biobase-international.com/hgmd/ pro/gene.php?gene= $C P$, access date: Apr.5, 2021), including 38 missense/nonsense variants, 12 splicing variants, 14 small deletions, 5 small insertions, 1 small indels, 2 gross deletion and 2 gross insertions. There are only around 100 cases reported worldwide to date since 1987 when the first case was published in Japan.(Miyajima et al. 1987)

To describe its heterogeneity, some patients started to show signs of microcytic anemia as early as in childhoods while some turned for professional help only for memory loss or depression in their late 60s. The progression of ACP is slow and diverse, and its genotype-phenotype correlation remains unclear. Meanwhile, the development of neurological symptoms causes serious and irreversible effects on affected individuals. Therefore, early diagnosis and management such as iron chelation can be crucial in delaying or preventing the worsening of symptoms and improving the overall quality of life of patients. The difficulty of diagnosis lies not just in the standards of laboratory examinations or image analysis, or even genetic detection, but more in whether the disease can be considered in differential diagnosis process. The establishment of an ACP diagnosis requires typical clinical findings and identification of biallelic pathogenic variants in $C P$ by genetic testing. Clinical findings include diabetes mellitus, anemia, neurologic symptoms and characteristic retinal degeneration. It is believed that laboratory test results such as low transferrin saturation, hyperferritinemia, and low or undetectable serum ceruloplasmin can be more sensitivity in the diagnosis.(Marchi et al. 2019)

Here, we presented a Chinese ACP family and reported a new pathogenic variant. Then we gathered case reports and articles within the last decade to present them in a more systematic way for further research, and more importantly, to summarize a better pattern for the early diagnosis of ACP, in order to help more patients and physicians lowering the costs caused by missed or misdiagnosis.

\section{Methods}

\section{Subject and genetic analysis}

The family was recruited from the Second Affiliated Hospital of Zhejiang University School of Medicine. Clinical data of the proband, including related laboratory tests, Unified Wilson's Disease Rating Scale (UWDRS)(Członkowska et al. 2007) results, brain magnetic resonance imaging (MRI), and ophthalmic findings were obtained. Genomic DNA was extracted from peripheral EDTA-treated blood with Blood Genomic Extraction Kit (Qiagen) according to the manufactures' instructions. Whole exome sequencing (WES) was performed using Agilent SureSelectTM Human All Exon v6 kit on the Illumina HiSeq X Ten platform (XY Biotechnology Co. Ltd, Hangzhou, China). Subsequent variant calling, alignment and annotation were analyzed according to our previously reported protocol.(Jiang et al. 2019) Sanger sequencing was performed on an ABI 3500xL Dx Genetic Analyzer (Applied Biosystems) to validate the potential variants, and the procedure was described previously.(Dong et al. 2016) The study was approved by the corresponding ethics committee and the informed consents were obtained from the participants.

\section{Literature review design and data analysis}

The PubMed databases was searched for published cases of ACP from January 2010 to November 2020. Keywords used are aceruloplasminemia and ceruloplasmin deficiency. All articles or case reports written in English were reviewed. Search was also extended by screening the reference list of included published articles. Cases without genetic detection and complete diagnostic and treatment process were excluded. Then a total of 50 cases from 30 articles(Watanabe et al. 2010, 2018; Bethlehem et al. 2010; Hida et al. 2010; Finkenstedt et al. 2010; Ogimoto et al. 2011; Suzuki et al. 2013; Fujita et al. 2013; 
Rusticeanu et al. 2014; Kerkhof and Honkoop 2014; Matsushima et al. 2014; Meral Gunes et al. 2014; Tai et al. 2014; Lindner et al. 2015; Melgari et al. 2015; Vroegindeweij et al. 2015; Pelucchi et al. 2016, 2018; Hayashida et al. 2016; Kassubek et al. 2017; Poli et al. 2017; Kim et al. 2017; Riboldi et al. 2018; Yamamura et al. 2018; Ronquillo et al. 2019; Stelten et al. 2019; Vila Cuenca et al. 2020; Ondrejkovičová et al. 2020; Zhou et al. 2020; Miyake et al. 2020) were summarized in Table 1. Patient characteristics and case descriptions were extracted manually for further analysis. Qualitative analysis was used to analyze various symptoms and test results, expressing the results in terms of positives and negatives. The statistical items included symptoms (anemia, diabetes, neurological symptoms, retinopathy, liver disease) and examination findings (low to undetectable serum ceruloplasmin, low serum iron and/or hyperferritinemia, intracranial iron deposits, intrahepatic iron deposits) in 50 cases. Quantitative analysis was used for statistics on the earliest age of symptom onset, age of neurological symptoms onset and age of diagnosis. In order to ensure the authenticity and accuracy of the statistics, if a specific point in time was not mentioned in the article or supplementary, the case is excluded from the relevant data statistics. For example, in the calculation of the age of earliest symptom onset, if the information is not reflected in the case description or described vaguely such as "childhood", this case will be excluded. Analysis of variance (ANOVA) was used to compare the characteristics of the groups that met statistical standard. Ages are expressed as mean values. Statistical significance was defined as a $p$ value $<0.05$.

\section{Results}

\section{Genetic findings}

After WES analysis, we found that the index patient (Fig.1a) carried two heterozygous variants (c.606dupA and c.2689delC) within CP gene, which were validated by Sanger sequencing. The known frameshift variant c.606dupA (Fig.1b) in exon 3 results in the repetition of adenine in the coding region 606 , the change of amino acid 203 from aspartic acid to arginine and the creation of a new reading frame, ending at the downstream codon 5 . The nonsense variant c.2689delC (Fig.1c) in exon 6, resulting in the change of 897 amino acid from leucine to termination, is first reported worldwide. This novel variant was absent from public database including Exome Aggregation Consortium (ExAC), Genome Aggregation Database (gnomAD), and our in-house WES database containing 500 Chinese controls. The two variants were classified as pathogenic variants according to the American College of Medical Genetics and Genomics (ACMG) standards and guidelines. The son of the index patient was genetically tested to have a heterozygous variant c.2689delC.

\section{Clinical features}

The index patient is a 53-year-old Chinese woman carrying two heterozygous pathogenic variants within $C P$ gene, who was genetically diagnosed with ACP. She presented memory loss for three months when first visit in our department of neurology two years ago. Brain MRI showed excessive intracranial paramagnetic material deposition. She had a 19-year history of type 1 diabetes, diabetic ketoacidosis, diabetic retinopathy and mild anemia. Ceruloplasmin was low as $18 \mathrm{mg} / \mathrm{L}$, serum ferritin was high as $858.3 \mathrm{ng} / \mathrm{mL}$, and serum iron was $6.73 \mathrm{mmol} / \mathrm{L}$. Therefore, ACP was considered in differential diagnosis with Wilson's disease (WD). UWDRS score was 17/320. In addition, cardiac doppler ultrasound showed that the patient had atrial septal defect.

One and half year after the diagnosis, the patient rehospitalized for developing walking instability, accompanied by involuntary shaking of hands, anxiety, and occasional sudden tension or fear. Brain MRI and susceptibility weighted Imaging (SWI) showed iron deposition in nuclei, thalamus, red nucleus and substantia nigra of bilateral basal ganglia, and iron deposition on brain surface (Fig.1d-f). Hepatic MRI and diffusion-weighted imaging (DWI) showed hepatomegaly with reduced T2WI signal (Fig.1g). The UWDRS score progressed to 70/320, other psychological scales indicated poor mood, anxiety and emotional indifference. Later ophthalmic consultation showed no obvious abnormality of retina (Fig.1h, i).

\section{Literature review}

The cases with genetic testing and complete diagnostic and treatment process reported in English in the past decade were included, and 49 cases out of 30 articles were screened out (Table 1). Adding the case in the current study, 33 out of 50 cases had neurological symptoms. As shown in Table 2 , the average age of onset (AAO) of symptoms was 35.2 years, and the average age of diagnosis was 48.8 years, which means that the average delay was 13.6 years. Among them, the average delay of 33 patients with neurological symptoms was 15.7 years, while that of 17 patients without neurological symptoms was 8.8 years.

The AAO of neurological symptoms was 52.2 years while that of anemia is hard to determine, with some patients being found anemic in their thirties and forties, and some cases being described as having developed anemia during a vague period of childhood. Therefore, the specific AAO of anemia cannot be calculated with certainty. Based on the 15 cases in which the AAO of anemia was described in detail, their average AAO is 29.7 years old. Similarly, the AAO of diabetes mellitus was not determined at the time of consultation or was not reflected in the case reports for some patients, and the average AAO was 37.3 years in the 16 cases with detailed description. These two values above can provide certain reference value.

In addition, from the information extracted from these 50 cases, we also got the first diagnosis departments of the patients, which appeared in the department of hematology, endocrinology, neurology, and other (orthopedics, gastroenterology, etc.). Due to the data volume and uncertainty of description, it is difficult to calculate a convincing proportion. Neurological symptoms occurred in $66 \%$ of patients, anemia in $82 \%$, diabetes in $70 \%$, and retinal disease in $28 \%$. Except the undescribed or untested cases, almost all patients had low transferrin saturation, hyperferritinemia, low or undetectable serum ceruloplasmin, and imaging findings of abnormal iron deposition in the brain and liver. Cognitive decline (77\%) was most common among patients with neurological symptoms, followed by ataxia in $53 \%$, hyperkinetic movement disorders in $43 \%$, parkinsonism in $33 \%$, and psychiatric changes in $17 \%$. Most patients have more than one kind of neurological symptom.

\section{Discussion}


Aceruloplasminemia (ACP) is a rare iron deposition disorder with a variety of clinical manifestations, and there is not a wealth of cases or data available for study worldwide right now. Here we presented a Chinese patient with a relatively typical course of the disease and a complete medical record and reported a novel pathogenic variant (c.2689delC) in CP gene. The patient developed anemia, diabetes, and neurological symptoms in sequence, which was consistent with the course of ACP as discussed in the literature review. In the literature study, we have found that complete data records are very important for further studies, and the examination of iron deposition in multiple system after diagnosis is also conducive to physicians' understanding of the patient's condition. We recommend a comprehensive examination for ACP patients to be assessed and confirmed.

Previously, reviews from Japan,(Kono 2013) Italy,(Pelucchi et al. 2018; Marchi et al. 2019) the Netherlands,(Vroegindeweij et al. 2015) the United States(Borges et al. 2019) and other countries(Vila Cuenca et al. 2020) also have analyzed reported cases in terms of clinical manifestations and treatment efficiency. These literatures have reached remarkable results, which have greatly promoted the research of ACP. In this study, we selected the more recent cases in the past decade for further study of diagnosis and treatment, aiming to reduce the missed diagnosis or misdiagnosis of ACP. Because iron deposition in ACP results in multiple symptoms, the patient's first clinical visit can be diverse that it is difficult to concatenate multiple manifestations in a monistic manner, resulting in an average delay of 13.6 years from first symptoms to diagnosis in these 50 cases. In our patient's case, for example, the early onset of anemia had no clear etiology, and the later onset of type I diabetes failed to correlate with the anemia, and it wasn't until the patient developed neurological symptoms in the late stages of the disease that we were able to really connect all of the patient's symptoms together and consider the diagnosis of ACP.

Our findings corroborate the conclusions of previous partial reviews that there is a time window for the onset of ACP(Vroegindeweij et al. 2015) and that the order of onset of anemia, diabetes, and neurological symptoms in this study averaged 29.7, 37.3, and 52.2 years, respectively, and that patients did not necessarily experience all symptoms. Current research on the relationship between genotypes and phenotypes and the pathogenesis of ACP is insufficient to explain this symptomatic profile. However, the analysis of this information allows us to make a definitive diagnosis at an earlier stage of the disease. In this literature review, about $82.0 \%$ of the patients have anemia at the final diagnosis, but only about $26.0 \%$ diagnosed ACP with anemia as the main complaint. Although $70.0 \%$ of the patients had diabetes at the final diagnosis, only $10 \%$ diagnosed ACP with diabetes as the chief complaint. At the time of diagnosis, $66.0 \%$ of the patients have neurological symptoms, and $60.0 \%$ of them have been diagnosed due to neurological symptoms, accounting for the largest proportion.

Except for the cases that were not clearly described or recorded, low or undetectable ceruloplasmin and low serum iron and/or hyperferritinemia were found in all confirmed cases. The sensitivity of these two laboratory tests is very credible. It is also very important to make a differential diagnosis with other entities that present similar results, such as Wilson's disease, Menke's disease for low serum CP, and metabolic syndrome, alcoholism inflammatory disorders or hemochromatosis for hyperferritemia. Neurological symptoms commonly include cognitive decline, hyperkinetic movement disorders, parkinsonism, ataxia and psychiatric changes, which may be caused by iron deposition in different areas of the brain, such as the cortex, hippocampus, basal ganglia, etc. The relevance of specific imaging analyses and genotypes needs to be further investigated.

It is worth mentioning that with the development of genetic testing technology, the age at the time of diagnosis with ACP can be brought forward. In this review, several cases successfully managed early diagnosis in patients with anemia, diabetes or liver disease, some asymptomatic cases were also genetically diagnosed in the family screening. For example, the first ACP patient in Turkey was successfully diagnosed at age of 16 by screening for causes of anemia, using laboratory tests and genetic testing.(Meral Gunes et al. 2014) A 20-year-old patient in Australia was treated for a sustained increase in ferritin and a mild increase in alanine aminotransferase, he was eventually diagnosed with ACP through clinical manifestations.(Lindner et al. 2015) In another case, a Japanese woman suffered from anemia at the age of 21 , diabetes at the age of 23 , and retinopathy at the age of 25 . At the age of 33 , she had genetic diagnosis at the same time with her sisters.(Hayashida et al. 2016) A 41-year-old patient in Slovakia was treated for recurrent abortion due to persistent small cell hypopigmentation anemia. After careful differential diagnosis, the clinical and genetic diagnosis of ACP was obtained.(Ondrejkovičová et al. 2020) These cases are examples of successful early diagnosis. The purpose of this study is to improve the early diagnosis and raise more attention for ACP, reducing the irreversible damage in patients caused by missed diagnosis or misdiagnosis. Further analysis of the treatment and prognosis of these cases are needed, and the relevant molecular and animal models are being developed and studied, which will help to improve our understanding of the disease.

\section{Conclusion}

Patients with ACP can visit the clinic for different complaints. Anemia and diabetes usually precede the onset of dangerous neurological symptoms. Besides, biochemical triad, namely anemia, low to undetectable serum ceruloplasmin, low serum iron and/or hyperferritinemia, shows better sensitivity in diagnosis than clinical triad, namely diabetes, neurological symptoms and retinal degeneration, which can benefit the prompt diagnosis in the early stage of the disease.

\section{Declarations}

\section{Funding}

This work was supported by the research foundation for distinguished scholar of Zhejiang University to Zhi-Ying Wu (188020-193810101/089, Hangzhou).

\section{Conflict of interest}

The authors have no potential conflicts of interest to disclose.

\section{Data availability}

All data generated or analyzed during this study are included in this published article. 


\section{Authors' contributions}

All authors contributed to the study conception and design. Material preparation, data collection and analysis were performed by Wan-Qing Xu, Wang Ni, RouMin Wang, Yi Dong and Zhi-Ying Wu. The first draft of the manuscript was written by Wan-Qing Xu and all authors commented on previous versions of the manuscript. All authors read and approved the final manuscript.

\section{Ethics approval}

The study was approved by the ethics committee of the Second Affiliated Hospital of Zhejiang University School of Medicine.

\section{Consent to participate}

Informed consent was obtained from all individual participants included in the study.

\section{Consent for publication}

Patients signed informed consent regarding publishing their data and photographs.

\section{References}

1. Bethlehem C, van Harten B, Hoogendoorn M (2010) Central nervous system involvement in a rare genetic iron overload disorder. Neth J Med 68:316-318

2. Borges MD, Albuquerque DM, Lanaro C et al (2019) Clinical relevance of heterozygosis for aceruloplasminemia. Am J Med Genet 180:266-271. https://doi.org/10.1002/ajmg.b.32723

3. Członkowska A, Tarnacka B, Möller JC et al (2007) Unified Wilson's Disease Rating Scale - a proposal for the neurological scoring of Wilson's disease patients. Neurol Neurochir Pol 41:1-12

4. Dong Y, Ni W, Chen W-J et al (2016) Spectrum and classification of ATP7B variants in a large cohort of Chinese patients with Wilson's Disease guides genetic diagnosis. Theranostics 6:638-649. https://doi.org/10.7150/thno.14596

5. Finkenstedt A, Wolf E, Höfner E et al (2010) Hepatic but not brain iron is rapidly chelated by deferasirox in aceruloplasminemia due to a novel gene mutation. J Hepatol 53:1101-1107. https://doi.org/10.1016/j.jhep.2010.04.039

6. Fujita K, Osaki Y, Harada M et al (2013) Brain and liver iron accumulation in aceruloplasminemia. Neurology 81:2145-2146. https://doi.org/10.1212/01.wnl.0000437304.30227.bd

7. Hayashida M, Hashioka S, Miki H et al (2016) Aceruloplasminemia with psychomotor excitement and neurological sign was improved by minocycline (Case Report). Med (Baltim) 95:e3594. https://doi.org/10.1097/MD.0000000000003594

8. Hida A, Kowa H, Iwata A et al (2010) Aceruloplasminemia in a Japanese woman with a novel mutation of CP gene: clinical presentations and analysis of genetic and molecular pathogenesis. J Neurol Sci 298:136-139. https://doi.org/10.1016/j.jns.2010.08.019

9. Jiang B, Zhou J, Li H-L et al (2019) Mutation screening in Chinese patients with familial Alzheimer's disease by whole-exome sequencing. Neurobiol Aging 76:215.e15-215.e21. https://doi.org/10.1016/j.neurobiolaging.2018.11.024

10. Kassubek R, Uttner I, Schönfeldt-Lecuona C et al (2017) Extending the aceruloplasminemia phenotype: NBIA on imaging and acanthocytosis, yet only minor neurological findings. J Neurol Sci 376:151-152. https://doi.org/10.1016/j.jns.2017.03.019

11. Kerkhof M, Honkoop P (2014) Never forget aceruloplasminemia in case of highly suggestive Wilson's disease score. Hepatology 59:1645-1647. https://doi.org/10.1002/hep.26719

12. Kim HK, Ki CS, Kim YJ, Lee MS (2017) Radiological findings of two sisters with aceruloplasminemia presenting with chorea. Clin Neuroradiol 27:385-388. https://doi.org/10.1007/s00062-017-0573-0

13. Kono S (2013) Aceruloplasminemia. In: International Review of Neurobiology. Elsevier, pp 125-151

14. Lindner U, Schuppan D, Schleithoff $L$ et al (2015) Aceruloplasminaemia: a family with a novel mutation and long-term therapy with deferasirox. Horm Metab Res 47:303-308. https://doi.org/10.1055/s-0034-1383650

15. Marchi G, Busti F, Lira Zidanes A et al (2019) Aceruloplasminemia: A severe neurodegenerative disorder deserving an early diagnosis. Front Neurosci 13:325. https://doi.org/10.3389/fnins.2019.00325

16. Matsushima A, Yoshida T, Yoshida K et al (2014) Superficial siderosis associated with aceruloplasminemia. Case report. J Neurol Sci 339:231-234. https://doi.org/10.1016/j.jns.2014.02.014

17. Melgari J-M, Marano M, Quattrocchi CC et al (2015) Movement disorders and brain iron overload in a new subtype of aceruloplasminemia. Parkinsonism Relat Disord 21:658-660. https://doi.org/10.1016/j.parkreldis.2015.03.014

18. Meral Gunes A, Sezgin Evim M, Baytan B et al (2014) Aceruloplasminemia in a Turkish adolescent with a novel mutation of ceruloplasmin gene: the first diagnosed case from Turkey. J Pediatr Hematol Oncol 36:e423-e425. https://doi.org/10.1097/MPH.0000000000000053

19. Miyajima H, Hosoi Y (1993) Aceruloplasminemia. In: Adam MP, Ardinger HH, Pagon RA et al (eds) GeneReviews ${ }^{\circledR}$. University of Washington, Seattle

20. Miyajima H, Nishimura Y, Mizoguchi K et al (1987) Familial apoceruloplasmin deficiency associated with blepharospasm and retinal degeneration. Neurology 37:761-767. https://doi.org/10.1212/wnl.37.5.761 
21. Miyake Z, Nakamagoe K, Yoshida K et al (2020) Deferasirox might be effective for microcytic anemia and neurological symptoms associated with aceruloplasminemia: A case report and review of the literature. Intern Med 59:1755-1761. https://doi.org/10.2169/internalmedicine.4178-19

22. Ogimoto M, Anzai K, Takenoshita $\mathrm{H}$ et al (2011) Criteria for early identification of aceruloplasminemia. Intern Med 50:1415-1418. https://doi.org/10.2169/internalmedicine.50.5108

23. Ondrejkovičová M, Dražilová S, Drakulová M et al (2020) New mutation of the ceruloplasmin gene in the case of a neurologically asymptomatic patient with microcytic anaemia, obesity and supposed Wilson's disease. BMC Gastroenterol 20:95. https://doi.org/10.1186/s12876-020-01237-8

24. Pelucchi S, Mariani R, Ravasi G et al (2018) Phenotypic heterogeneity in seven Italian cases of aceruloplasminemia. Parkinsonism Relat Disord 51:36-42. https://doi.org/10.1016/j.parkreldis.2018.02.036

25. Pelucchi S, Pelloni I, Arosio C et al (2016) Does aceruloplasminemia modulate iron phenotype in thalassemia intermedia? Blood Cells Mol Dis 57:112114. https://doi.org/10.1016/j.bcmd.2015.12.011

26. Poli L, Alberici A, Buzzi P et al (2017) Is aceruloplasminemia treatable? Combining iron chelation and fresh-frozen plasma treatment. Neurol Sci 38:357360. https://doi.org/10.1007/s10072-016-2756-x

27. Riboldi GM, Anstett K, Jain R et al (2018) Aceruloplasminemia and putaminal cavitation. Parkinsonism Relat Disord 51:121-123. https://doi.org/10.1016/j.parkreldis.2018.03.003

28. Ronquillo CC, Sauer L, Morgan D et al (2019) Absence of macular degeneration in a patient with aceruloplasminemia. Retina (Philadelphia Pa) 39:18241828. https://doi.org/10.1097/IAE.0000000000002628

29. Rusticeanu M, Zimmer V, Schleithoff L et al (2014) Novel ceruloplasmin mutation causing aceruloplasminemia with hepatic iron overload and diabetes without neurological symptoms. Clin Genet 85:300-301. https://doi.org/10.1111/cge.12145

30. Stelten BML, van Ommen W, Keizer K (2019) Neurodegeneration with brain iron accumulation: a novel mutation in the ceruloplasmin gene. JAMA Neurol 76:229-230. https://doi.org/10.1001/jamaneurol.2018.3230

31. Suzuki Y, Yoshida K, Aburakawa Y et al (2013) Effectiveness of oral iron chelator treatment with deferasirox in an aceruloplasminemia patient with a novel ceruloplasmin gene mutation. Intern Med 52:1527-1530. https://doi.org/10.2169/internalmedicine.52.0102

32. Tai M, Matsuhashi N, Ichii O et al (2014) Case of presymptomatic aceruloplasminemia treated with deferasirox. Hepatol Res 44:1253-1258. https://doi.org/10.1111/hepr.12292

33. Vila Cuenca M, Marchi G, Barqué A et al (2020) Genetic and clinical heterogeneity in thirteen new cases with aceruloplasminemia. Atypical anemia as a clue for an early diagnosis. Int J Mol Sci 21:. https://doi.org/10.3390/ijms21072374

34. Vroegindeweij LHP, van der Beek EH, Boon AJW et al (2015) Aceruloplasminemia presents as Type 1 diabetes in non-obese adults: a detailed case series. Diabet Med 32:993-1000. https://doi.org/10.1111/dme.12712

35. Wang B, Wang X-P (2019) Does ceruloplasmin defend against neurodegenerative diseases? Curr Neuropharmacol 17:539-549. https://doi.org/10.2174/1570159X16666180508113025

36. Watanabe M, Asai C, Ishikawa K et al (2010) Central diabetes insipidus and hypothalamic hypothyroidism associated with aceruloplasminemia. Intern Med 49:1581-1585. https://doi.org/10.2169/internalmedicine.49.3508

37. Watanabe M, Ohyama K, Suzuki M et al (2018) Aceruloplasminemia with abnormal compound heterozygous mutations developed neurological dysfunction during phlebotomy therapy. Intern Med 57:2713-2718. https://doi.org/10.2169/internalmedicine.9855-17

38. Yamamura A, Kikukawa Y, Tokunaga K et al (2018) Pancytopenia and myelodysplastic changes in aceruloplasminemia: a case with a novel pathogenic variant in the Ceruloplasmin Gene. Intern Med 57:1905-1910. https://doi.org/10.2169/internalmedicine.9496-17

39. Zhou L, Chen Y, Li Y et al (2020) Intracranial iron distribution and quantification in aceruloplasminemia: A case study. Magn Reson Imaging 70:29-35. https://doi.org/10.1016/j.mri.2020.02.016

\section{Tables}


Table 1

Fifty cases including 49 cases reported in the past decade

\begin{tabular}{|c|c|c|c|c|c|c|c|c|c|c|c|c|c|c|}
\hline $\begin{array}{l}\text { Case } \\
\text { No. }\end{array}$ & Country & Gender & Cp gene variants & $\begin{array}{l}\text { AAFM, } \\
\text { years }\end{array}$ & $\begin{array}{l}\text { AAFNS, } \\
\text { years }\end{array}$ & $\begin{array}{l}\text { AAD, } \\
\text { years }\end{array}$ & DM & NS & RD & Anemia & $\begin{array}{l}\text { Brain } \\
\text { iron } \\
\text { overload }\end{array}$ & $\begin{array}{l}\text { LTU } \\
\text { serum } \\
\text { CP }\end{array}$ & $\begin{array}{l}\text { LSI } \\
\text { with } \\
\text { /or } \\
\text { HF }\end{array}$ & $\begin{array}{l}\text { Liver } \\
\text { iron } \\
\text { overl }\end{array}$ \\
\hline 1 & Japan & $\mathrm{F}$ & c. $3107 \mathrm{G}>\mathrm{A}$ & 33 & 51 & 58 & + & + & + & NA & + & + & + & + \\
\hline 2 & Netherlands & $\mathrm{F}$ & c. $1948 \mathrm{G}>\mathrm{A}$ & NA & NA & 59 & NA & + & - & + & + & + & + & + \\
\hline 3 & Austria & M & c. $2554+1 G>T$ & 26 & 43 & 47 & + & + & + & - & + & + & + & + \\
\hline 4 & Japan & $\mathrm{F}$ & c.319delT & 19 & 49 & 52 & + & + & NA & + & + & + & + & + \\
\hline 5 & Japan & $\mathrm{F}$ & c. $2630 \mathrm{G}>\mathrm{A}$ & NA & NA & 68 & + & + & + & + & + & NA & NA & + \\
\hline 6 & Japan & M & c.2185delC & NA & 53 & 59 & - & + & NA & + & + & + & + & + \\
\hline 7 & Japan & $\mathrm{F}$ & c. $2630 \mathrm{G}>\mathrm{A}$ & NA & 60 & 63 & + & + & - & + & + & + & + & + \\
\hline 8 & Italy & $\mathrm{F}$ & deletion of exon 12 & NA & NA & 51 & + & + & + & + & + & + & + & - \\
\hline 9 & Italy & M & $\begin{array}{l}\text { c.1865-312_2077 + } \\
\text { 351del }\end{array}$ & 12 & 50 & 52 & + & + & NA & + & + & + & + & + \\
\hline 10 & Italy & M & $\begin{array}{l}\text { c.848G > } \mathrm{A} ; \\
\text { c.2689_2690delCT }\end{array}$ & 24 & NA & 59 & + & + & + & - & + & + & + & + \\
\hline 11 & Netherlands & M & c. $1948 \mathrm{G}>\mathrm{A}$ & NA & NA & 56 & + & + & - & + & + & + & + & + \\
\hline 12 & Netherlands & $M$ & c. $1948 \mathrm{G}>\mathrm{A}$ & NA & 48 & 50 & + & + & NA & NA & NA & NA & NA & NA \\
\hline 13 & Netherlands & M & c. $1948 \mathrm{G}>\mathrm{A}$ & NA & 54 & 56 & + & + & NA & NA & NA & NA & NA & NA \\
\hline 14 & Japan & $\mathrm{F}$ & $\begin{array}{l}\text { a mutation in exon } \\
\text { 12(details NA) }\end{array}$ & 23 & 43 & 33 & + & + & + & + & + & + & + & + \\
\hline 15 & Korea & $\mathrm{F}$ & $\begin{array}{l}\text { c. } 2630 G>A ; c .1864+ \\
1 G>C\end{array}$ & NA & 56 & 57 & - & + & + & + & + & + & + & NA \\
\hline 16 & Korea & $\mathrm{F}$ & $\begin{array}{l}\text { c. } 2630 G>A ; c .1864+ \\
1 G>C\end{array}$ & NA & 55 & 57 & + & + & + & + & + & + & + & NA \\
\hline 17 & Germany & $\mathrm{F}$ & c. $1049 \mathrm{C}>\mathrm{A}$ & 64 & 71 & 72 & + & + & NA & + & + & + & + & + \\
\hline 18 & Japan & $\mathrm{F}$ & $\begin{array}{l}\text { c.1286_1290insTATAC; } \\
\text { c.2185delC }\end{array}$ & 50 & 67 & 68 & + & + & - & & + & + & + & + \\
\hline 19 & Netherlands & NA & c. $1192-1196 \mathrm{del}$ & NA & NA & 55 & + & + & - & + & + & + & + & + \\
\hline 20 & USA & $\mathrm{F}$ & c. $1632 \mathrm{del} ;$ c. $391 \mathrm{G}>\mathrm{A}$ & NA & 56 & 61 & + & + & NA & + & + & + & + & + \\
\hline 21 & Japan & $\mathrm{F}$ & c. $1670 \mathrm{~T}>\mathrm{G}$ & 69 & 72 & 72 & + & + & NA & + & + & + & + & + \\
\hline 22 & USA & $\mathrm{F}$ & c. $395-1 \mathrm{G}>\mathrm{A}$ & 56 & 63 & 63 & NA & + & + & + & NA & NA & NA & NA \\
\hline 23 & China & $\mathrm{F}$ & c.606dupA & 32 & 52 & 53 & + & + & NA & + & + & + & + & + \\
\hline 24 & Lithuanian & $\mathrm{F}$ & $\begin{array}{l}\text { c.1783_1787delGATAA; } \\
\text { c.2520_2523delAACA }\end{array}$ & 55 & 55 & 75 & + & + & + & + & + & + & + & NA \\
\hline 25 & India & M & c. $1864+5 G>A$ & 35 & 35 & 40 & + & + & - & + & + & + & + & + \\
\hline 26 & India & $M$ & c. $1864+5 G>A$ & 62 & 64 & 66 & + & + & - & + & + & + & + & + \\
\hline 27 & India & $\mathrm{F}$ & c. $1864+5 G>A$ & 57 & 57 & 61 & + & + & - & + & + & + & + & - \\
\hline 28 & Poland & $\mathrm{F}$ & c. $389 \mathrm{~A}>\mathrm{C}$ & 27 & 31 & 40 & - & + & - & + & + & + & + & NA \\
\hline 29 & Brazil & $\mathrm{F}$ & c. $2879-1 \mathrm{G}>\mathrm{T}$ & 36 & 36 & 37 & + & + & + & + & + & + & + & + \\
\hline 30 & India & $\mathrm{F}$ & c. $1679 \mathrm{G}>\mathrm{T}$ & 22 & 22 & 25 & - & + & - & + & + & + & + & + \\
\hline 31 & Pakistan & M & c. $1713+1$ delG & NA & NA & 16 & - & + & + & - & NA & + & + & + \\
\hline 32 & Japan & $M$ & c. $3107 \mathrm{G}<\mathrm{A}$ & 38 & 61 & 64 & + & + & + & + & + & + & + & + \\
\hline 33 & China & $\mathrm{F}$ & c.2689delC; c.606dupA & NA & 53 & 55 & 34 & + & - & + & + & + & + & + \\
\hline 34 & Japan & M & c.1282_1286dupTACAC & 42 & & 44 & + & & NA & NA & + & + & + & + \\
\hline 35 & Japan & M & c. $2641 \mathrm{G}>\mathrm{A}$ & 16 & & 35 & + & & - & + & + & + & + & + \\
\hline
\end{tabular}




\begin{tabular}{|c|c|c|c|c|c|c|c|c|c|c|c|c|c|c|}
\hline $\begin{array}{l}\text { Case } \\
\text { No. }\end{array}$ & Country & Gender & Cp gene variants & $\begin{array}{l}\text { AAFM, } \\
\text { years }\end{array}$ & $\begin{array}{l}\text { AAFNS, } \\
\text { years }\end{array}$ & $\begin{array}{l}A A D, \\
\text { years }\end{array}$ & DM & NS & $\mathrm{RD}$ & Anemia & $\begin{array}{l}\text { Brain } \\
\text { iron } \\
\text { overload }\end{array}$ & $\begin{array}{l}\text { LTU } \\
\text { serum } \\
\text { CP }\end{array}$ & $\begin{array}{l}\text { LSI } \\
\text { with } \\
\text { /or } \\
\text { HF }\end{array}$ & $\begin{array}{l}\text { Liver } \\
\text { iron } \\
\text { overl }\end{array}$ \\
\hline 36 & Germany & M & c.1211_1212dupTG & NA & & 39 & + & & - & + & + & + & + & + \\
\hline 37 & Turkish & $\mathrm{F}$ & c. $1306 \mathrm{C}>\mathrm{T}$ & 12 & & 16 & - & & - & + & + & + & + & + \\
\hline 38 & Germany & $\mathrm{F}$ & c. $2122 \mathrm{G}>\mathrm{A}$ & NA & & 43 & + & & - & + & + & + & + & + \\
\hline 39 & Germany & M & c. $2122 \mathrm{G}>\mathrm{A}$ & NA & & 39 & + & & - & + & + & + & + & + \\
\hline 40 & Germany & M & c. $2122 \mathrm{G}>\mathrm{A}$ & NA & & 24 & + & & - & + & + & + & + & + \\
\hline 41 & Italy & $\mathrm{F}$ & c. $1012 \mathrm{~T}>\mathrm{A}$ & 36 & & 36 & + & & - & + & + & + & + & + \\
\hline 42 & Italy & M & c. $2972 \mathrm{~T}>\mathrm{C}$ & 52 & & 52 & - & & - & + & - & + & + & + \\
\hline 43 & Italy & $\mathrm{F}$ & c. $1208+1 G>A$ & 37 & & 37 & - & & - & + & + & + & + & - \\
\hline 44 & Italy & M & c. $1208+1 G>A$ & 20 & & 20 & + & & - & - & + & + & + & - \\
\hline 45 & Slovakia & NA & c. $1664 G>A$ & NA & & 41 & - & & - & + & + & + & + & + \\
\hline 46 & Spain & $\mathrm{F}$ & c.2050_2051delAC & 15 & & 33 & - & & - & + & + & + & + & + \\
\hline 47 & Italian & M & 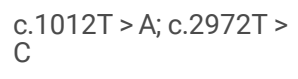 & 43 & & 46 & - & & - & + & - & + & + & + \\
\hline 48 & Italian & M & $\begin{array}{l}\mathrm{c} .2684 \mathrm{G}>\mathrm{C} ; \mathrm{c} .1602 \mathrm{~T}> \\
\mathrm{G}\end{array}$ & 32 & & 62 & - & & - & + & - & + & + & NA \\
\hline 49 & Brazil & $\mathrm{F}$ & c. $2879-1 G>T$ & NA & & 29 & - & & NA & - & + & + & + & + \\
\hline 50 & Brazil & $\mathrm{F}$ & c. $2756 \mathrm{~T}>\mathrm{C}$ & 14 & & 46 & + & & NA & + & + & + & + & NA \\
\hline
\end{tabular}

AAFM, age at first manifestation; AAFNS, age at first neurological symptoms; AAD, Age at diagnosis; DM, Diabetes mellitus; NS, neurological symptoms; RD, retinal degeneration; LTU serum CP, low to undetectable serum CP; LSI with/or HF, low serum iron with/or hyperferritinemia; NA, not available; +, positive; -, negative; *Case 1-33 are with neurological symptoms (including the case reported in this publication), case 34-50 are without neurological symptoms.

Table 2

Clinical feature of 50 aceruloplasminemia patients

\begin{tabular}{|c|c|c|c|}
\hline & All $(n=50)$ & $\begin{array}{l}\text { Patients with neurological symptoms } \\
(n=33)\end{array}$ & $\begin{array}{l}\text { Patients without neurological symptoms } \\
(n=17)\end{array}$ \\
\hline AAFM, years & 35.2 & 38.8 & 29.0 \\
\hline AAFNS, years & 52.2 & 52.2 & - \\
\hline$A A D$, years & 48.8 & 54.5 & $37.7 *$ \\
\hline Average delay, years & 13.6 & 15.7 & 8.8 \\
\hline \multirow[t]{5}{*}{ Neurological symptoms, \% } & $66 \%$ & Cognitive decline: $77 \%$ & \\
\hline & & Ataxia: $53 \%$ & \\
\hline & & Hyperkinetic movement disorders: $43 \%$ & \\
\hline & & Parkinsonism: 33\% & \\
\hline & & Psychiatric changes: $17 \%$ & \\
\hline Anemia, \% & $82 \%$ & & \\
\hline Diabetes mellitus, $\%$ & $70 \%$ & & \\
\hline Retinal disease, \% & $28 \%$ & & \\
\hline
\end{tabular}

${ }^{*} \mathrm{p}<0.01 ; \mathrm{AAFM}$, age at first manifestation; AAFNS, age at first neurological symptoms; AAD, age at diagnosis.

\section{Figures}




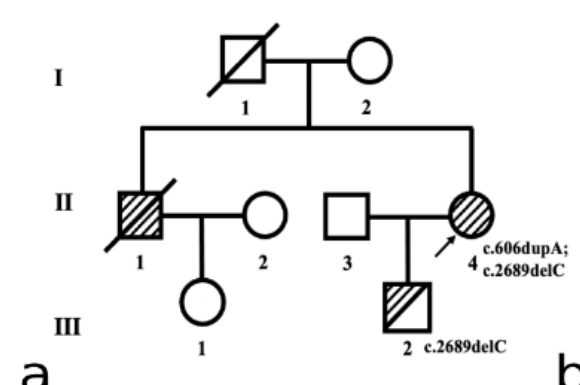

c.606dupA p.D203Rfs*

a
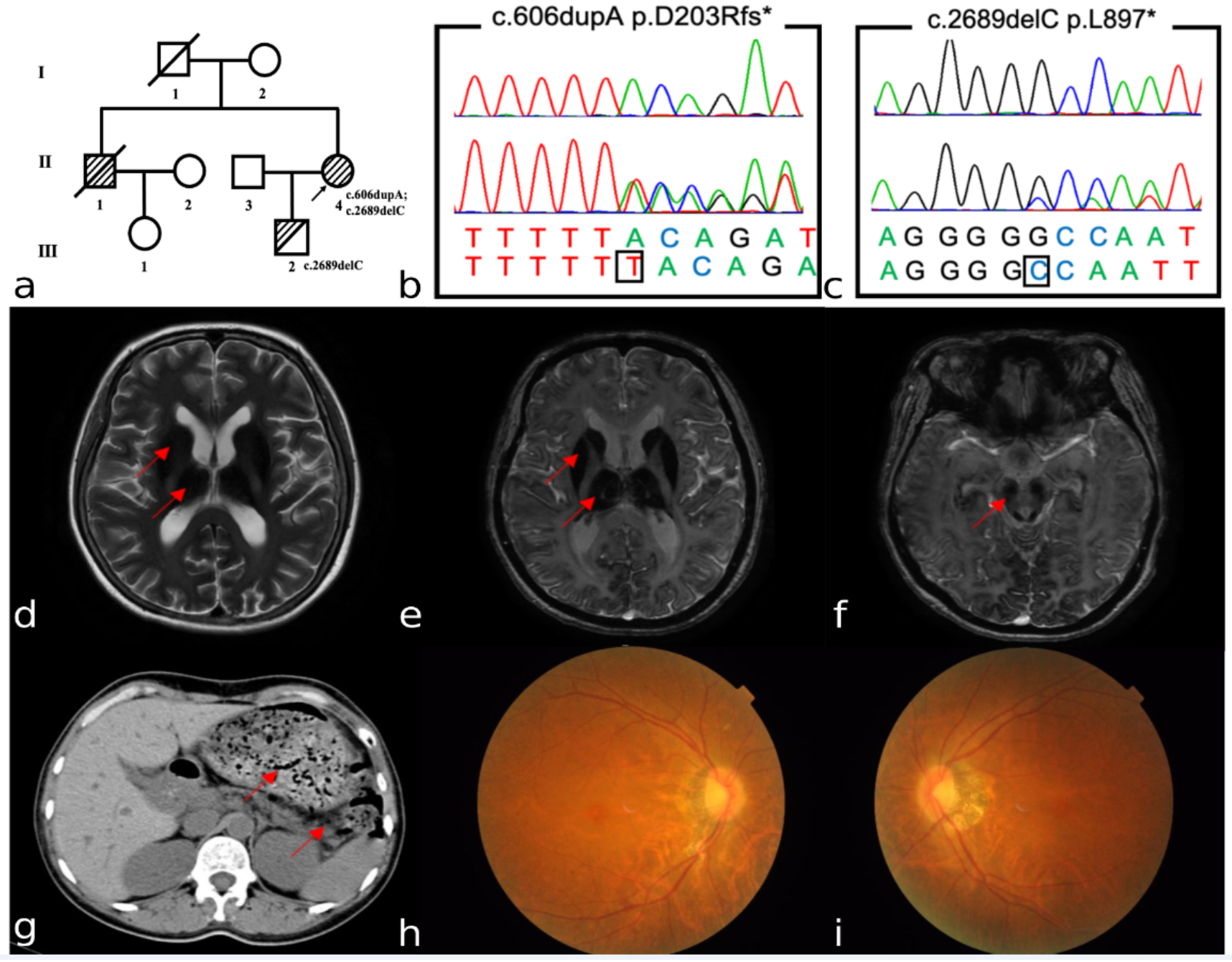

Figure 1

A Chinese patient with aceruloplasminemia carrying a novel pathogenic variant in ceruloplasmin. a. The pedigree of the patient. Square: males; circle: females; open symbol: unaffected individuals; filled symbol: affected patients; half filled symbol: individuals with heterozygous mutation; arrow: proband. b-c. Sequencing chromatograms of one novel variant and one known variant within CP. The upper panel depicts the reference sequence, and the lower panel represents the abnormal sequence. d. T2-weighted brain MRI, e. susceptibility weighted imaging (SWI) at the level of basal ganglia, and f. SWI at the level of pons showed iron deposition detected as a low-intensity signal (arrows) in bilateral basal ganglia, thalamus and bilateral dentate nucleus of cerebellum. $\mathrm{g}$. Abdominal CT showed increased density (arrows) of liver parenchyma and atrophy of pancreas. h-i. Fundus photographs of the right and left eyes suggest diabetic retinopathy. 